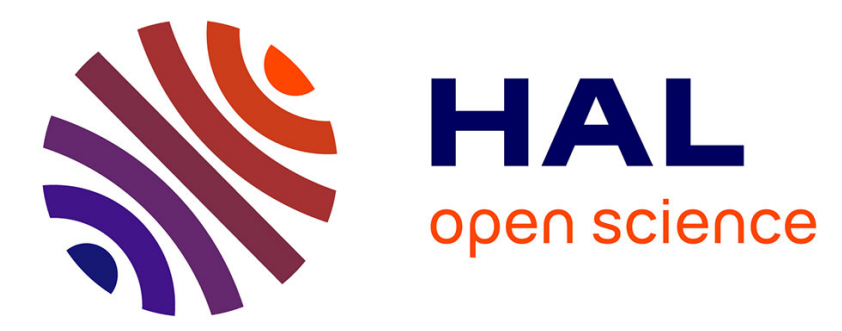

\title{
Structure and Dynamics of Water Confined in Imogolite Nanotubes
}

\author{
Laura Scalfi, Guillaume Fraux, Anne Boutin, François-Xavier Coudert
}

\section{To cite this version:}

Laura Scalfi, Guillaume Fraux, Anne Boutin, François-Xavier Coudert. Structure and Dynamics of Water Confined in Imogolite Nanotubes. Langmuir, 2018, 34 (23), pp.6748-6756. 10.1021/acs.langmuir.8b01115 . hal-02105073

\section{HAL Id: hal-02105073 \\ https://hal.science/hal-02105073}

Submitted on 20 Jun 2019

HAL is a multi-disciplinary open access archive for the deposit and dissemination of scientific research documents, whether they are published or not. The documents may come from teaching and research institutions in France or abroad, or from public or private research centers.
L'archive ouverte pluridisciplinaire HAL, est destinée au dépôt et à la diffusion de documents scientifiques de niveau recherche, publiés ou non, émanant des établissements d'enseignement et de recherche français ou étrangers, des laboratoires publics ou privés. 


\title{
Structure and Dynamics of Water Confined in Imogolite Nanotubes
}

\author{
Laura Scalfi, ${ }^{\dagger}$ Guillaume Fraux, ${ }^{\ddagger}$ Anne Boutin, ${ }^{, \dagger \dagger}$ and François-Xavier Coudert ${ }^{*,}$ \\ $\dagger$ †ASTEUR, Département de Chimie, École normale supérieure, PSL University, Sorbonne \\ Université, CNRS, 75005 Paris, France \\ $\ddagger$ Chimie ParisTech, PSL University, CNRS, Institut de Recherche de Chimie Paris, 75005 \\ Paris, France \\ E-mail: anne.boutin@ens.fr; fx.coudert@chimie-paristech.fr
}

\begin{abstract}
We have studied the properties of water adsorbed inside nanotubes of hydrophilic imogolite, an aluminum silicate clay mineral, by means of molecular simulations. We used a classical force field to describe the water and the flexible imogolite nanotube, and validated it against data obtained from first-principles molecular dynamics. With it, we observe a strong structuration of the water confined in the nanotube, with specific adsorption sites and a distribution of hydrogen bond patterns. The combination of number of adsorption sites, their geometry and the preferential tetrahedral hydrogen bonding pattern of water leads to frustration and disorder. We further characterize the dynamics of the water, as well as the hydrogen bonds formed between water molecules and the nanotube, which are found to be more than one order of magnitude longer than water-water hydrogen bonds.
\end{abstract}




\section{Introduction}

Imogolite is an aluminum silicate clay mineral, with formula $\mathrm{Al}_{2} \mathrm{SiO}_{3}(\mathrm{OH})_{4}$, that was first discovered in volcanic ashes in Japan. 1 It is the only known aluminosilicate material that spontaneously forms inorganic nanotubes, and there exists no planar equivalent material in nature - unlike carbon nanotubes, of which graphene is the planar form. Imogolite nanotubes are monodisperse in diameter, and can be readily synthesized with controlled length and diameter, for example by substituting silicon with germanium ${ }^{2}$. This precise control of the imogolite nanotube dimensions is interesting for applications that rely on onedimensional pore channels, in fields such as nanofluidic devices, membranes for filtration and separation, desalination, etc. Moreover, from a theoretical point of view, its hollow cylindrical topology and tuneable size make it a very attractive model to study the properties of fluids under confinement.

Although imogolites have been the subject of several experimental studies, only a few theoretical works have been carried out until now. In particular, there is relatively little data - experimental or computational — on the hydration of these nanotubes and the behavior of the confined water molecules inside the pore space. Imogolite nanotubes differ markedly from the more common carbon nanotubes in both geometry and chemistry, and the behavior of water inside their pores is still very much open. It is experimentally challenging to address these issues, especially differentiating the water inside the nanotubes from the water outside, and a computational approach through molecular modeling is therefore a natural complement to the published experimental results.

A single imogolite nanotube presents two surfaces, both available for adsorption. The outer surface is composed of a gibbsite-like sheet of aluminum octahedra. The inner surface is formed of silicon tetrahedra with one hydroxyl group pending and the three other corners of the tetrahedron linked to three aluminum octahedra. Therefore both surfaces are covered with hydroxyl groups that are expected to have a hydrophilic behavior. Based on electrostatic

calculations, authors have suggested that the inner surface is strongly hydrophilic whereas 
the outer surface might be more hydrophobic. $\frac{314}{14}$

Most of the theoretical studies on imogolite nanotubes focus on the energetics of empty nanotubes. The sharp monodispersity in nanotube diameters has been explained by both quantum chemistry and classical studies, that show the strain energy has a minimum for a given nanotube diameter, contrary to carbon nanotubes where the energetically favorable structure is that of infinite diameter (i.e., the graphene slab ${ }^{4}$ - $)$. Several studies also focused on computing vibrational spectra ${ }^{[5[8] 9}$ and studying the energetics and dynamics of the rolling of the nanotubes themselves. $\stackrel{10}{12}$ Finally, other works have pointed at more complex aspects, such as defects ${ }^{3}$ and deformation or hexagonalisation of the nanotubes. $\frac{5 \mid 13114}{5 .}$

Because adsorption on the outer surface of the nanotubes depends strongly on experimental conditions affecting the bundling of the nanotubes, and therefore the spacing between them, we will focus in the present work on the adsorption and behavior of water confined inside imogolite nanotubes. Moreover, the strong curvature and limited space inside the nanotube provide for strong confinement effects on which little experimental data is available. We have used a classical force field to describe the water and the flexible imogolite nanotube, which we validate against structural data obtained from first-principles molecular dynamics. From classical grand canonical Monte Carlo and molecular dynamics simulations, we observe a strong structuration of the water confined in the nanotube, with specific adsorption sites and a statistical distribution of hydrogen bond patterns. The combination of number of adsorption sites, their geometry and the preferential tetrahedral hydrogen bonding pattern of water leads to frustration and disorder. We also characterize the dynamics of the water, as well as the hydrogen bonds formed between water molecules and the nanotube. 

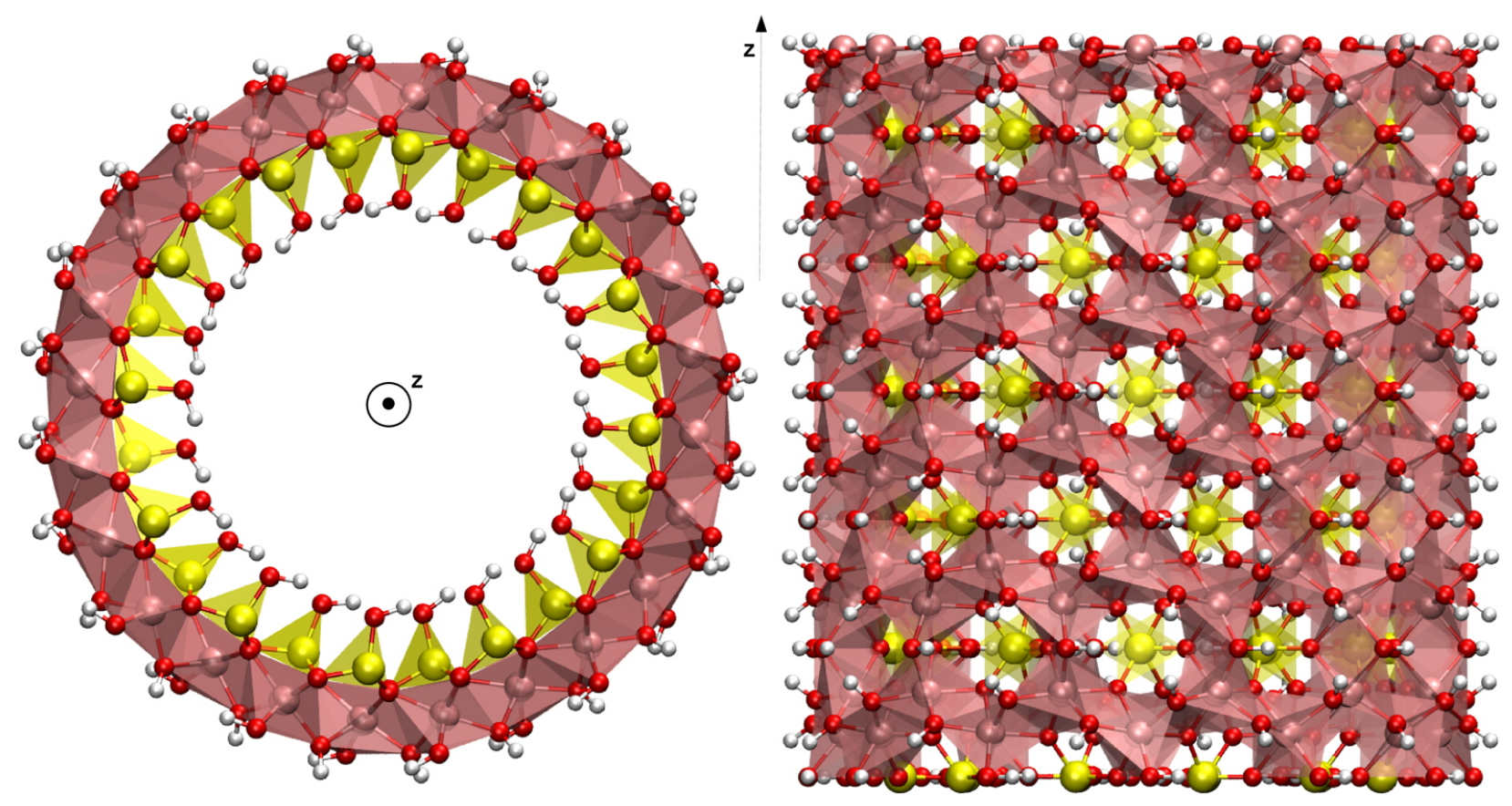

Figure 1: Imogolite nanotube $(n=12)$ with three unit cells along the tube axis $z$. Color code: Aluminum (pink), Silicon (yellow), Oxygen (red), Hydrogen (white). Note the hydrogen bonds between silanol groups on the inner surface (left panel).

\section{Systems}

\section{Imogolite structure}

Imogolites are aluminum silicate clay minerals with chemical formula $(\mathrm{OH})_{3} \mathrm{Al}_{2} \mathrm{O}_{3} \mathrm{SiOH}$. Their structure was first described by Cradwick et al. $\stackrel{15}{15}$ from electron diffraction measurements as a cylindrical assembly of silicon tetrahedra and aluminum octahedra (see Figure 1). This sheet spontaneously folds into a nanotube because of bond length mismatch and formation of hydrogen bonds. $\frac{10111}{1}$ The imogolite nanotubes are characterized using the same nomenclature as carbon nanotubes. Both natural and synthetic imogolite nanotubes exhibit a zig-zag folding, with a variable number $n$ of $(\mathrm{OH})_{3} \mathrm{Al}_{2} \mathrm{O}_{3} \mathrm{SiOH}$ units (called gibbsite units) along the nanotube circumference. The cylindrical unit cell then contains $2 n$ gibbsite units. Natural imogolite is a nanotube with size $n=12$, while depending on the details of the synthesis conditions, synthetic imogolites correspond to values of $n$ typically between 12 and 14 , and sometimes larger. 
In order to produce imogolite nanotube models, we started from the structure of Cradwick et al. $\frac{15}{15}$ for a $n=10$ nanotube with $C_{2 n}$ symmetry. We formed a flat gibbsite-like sheet by unfolding the nanotube and adding hydrogen atoms (not present on the electron diffraction data). We relaxed the slab geometry and unit cell with density functional theory (DFT, see computational details in next section) in the $C_{m}$ space group. From this relaxed planar structure, we rolled back a nanotube of size $n=12$. Using the Bilbao Crystallographic Server $\frac{16}{\text {, }}$ we identified the space groups of the nanotube to be $P 4 / m$. We relaxed the nanotube structure and cell parameters with periodic DFT calculations, with large inter-nanotube spacing $(60 \AA)$ so that there are no interactions between nanotubes. We show on Figure 1 , two views from top and side of the $n=12$ nanotube with three unit cells along the $z$ axis.

The internal surface of an imogolite nanotube can be described as a periodic sequence of silicon rings along the nanotube axis. Two adjacent rings are rotated of $\pi / n$. When dry, silanol groups within a ring form hydrogen bonds so that all the hydroxyl groups are in a plane normal to the nanotube axis, as shown in Figure 1. The internal diameter, computed between internal oxygens (noted $\mathrm{O}_{\text {int }}$ ), is $12.8 \AA$ and the external diameter, computed between external oxygens (noted $\mathrm{O}_{\text {ext }}$ ), is approximately $22 \AA$. Konduri et al. $\frac{17}{17}$ highlighted that as a consequence the inner pore is not smooth and uniform as for the carbon nanotube, but the pore is rugged: narrower where there are silanol groups and larger between these silicon rings. One can picture the internal cavity as a hollow cylinder with equally spaced circular furrows in the circumference.

\section{Nanotubes packing}

Imogolite nanotubes can have a length from $10 \mathrm{~nm}$ up to a few micrometers and experiments show that they tend to pack into bundles when dry. The periodic pattern seems to be a monoclinic assembly ${ }^{18 \mid 19}$ with $\beta \approx 78^{\circ}$. Given our focus on adsorption inside the nanotubes, following other theoretical studies, we chose to represent the nanotubes in a hexagonal pack-

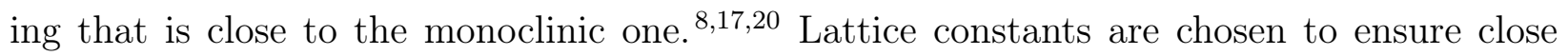


contact (but no overlap) between neighboring nanotubes, at $a=b=24.2 \AA$. This choice is consistent with experiments and other theoretical studies. Along the tube axis, we studied supercells with lattice parameters $c=n \times 8.486 \AA$ where $n=1,3$ or 5 (where the value of $8.486 \AA$ was determined by geometry optimization with variable cell).

\section{Simulation methods}

We performed simulations at two different levels of theory: at the quantum chemistry level, we performed Density Functional Theory calculations for both energy minimization as well as first principles molecular dynamics. We also used classical force field-based simulations, for both classical molecular dynamics and Monte Carlo simulations.

\section{Density Functional Theory calculations}

Energy minimization of the nanotubes and slabs were performed with Density Functional Theory (DFT) calculations with periodic boundary conditions and the use of symmetry to reduce computational cost. We used these calculations with the CRYSTAL14 ${ }^{21}$ software package. The exchange-correlation functional used was the solid-adapted generalized gradient approximation (GGA) PBEsol, and the basis set for all atoms ( $\mathrm{Si}, \mathrm{Al}, \mathrm{O}, \mathrm{H})$ was double- $\zeta$ valence polarized (DZVP).

We also performed DFT-based molecular dynamics simulations, aka first principles or $a b$ initio molecular dynamics (MD), as a way to generate reference data for comparison and validation of classical force fields. These simulations were run with CP2K.22 Temperature was kept constant at $300 \mathrm{~K}$ with a CSVR (canonical sampling through velocity rescaling) thermostat, ${ }^{23}$ with a time constant of $200 \mathrm{fs}$. The timestep was $0.5 \mathrm{fs}$, and the system was deuterated for computational convenience. After 5 ps of equilibration, production trajectories were accumulated for $30 \mathrm{ps}$. 


\section{Classical simulations}

Although DFT is a good model to extract the structure and short-time dynamics of the system, simulations longer than a few tens of picoseconds are not readily accessible. This is why we used classical simulations, based on a force field approximation of the intra- and inter-molecular interactions, to study structure and dynamics of water in imogolites at larger timescales. We ran MD simulations in the canonical $(N, V, T)$ ensemble with the LAMMPS code, ${ }^{24}$ using a timestep of 0.5 fs. After 100 ps of equilibration, we collected trajectories from $200 \mathrm{ps}$ to $50 \mathrm{~ns}$, depending on the properties studied in each case.

We also performed series of Grand Canonical Monte Carlo (GCMC) simulations with fixed chemical potential, volume and temperature $(\mu, V, T)$, to simulate the behavior of the system on equilibrium with a reservoir at a given pressure linked to the chemical potential. In the gas phase, water was considered to be an ideal gas, and the chemical potential is then easily linked to the gas pressure. ${ }^{25}$ Series of GCMC simulations were used to compute adsorption isotherms, with water vapor pressure going from 2 to $3600 \mathrm{~Pa}$.

To describe the interactions of the nanotube, we relied on the CLAYFF force field, 26

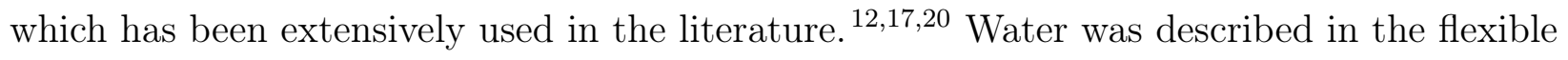
Single-Point Charge (fSPC) model, ${ }^{27}$ which is naturally suited for coupling with CLAYFF. CLAYFF is a general force field developed to model clay minerals, that have the same chemical nature of the imogolite. It relies almost exclusively on non-bonded interactions, where interatomic potentials are the sum of electrostatic (Coulombic) and dispersive-repulsive (Lennard-Jones 12-6) interactions. In addition to these non-bonding interactions, CLAYFF includes a harmonic bond term for hydroxyl bonds $(\mathrm{O}-\mathrm{H}$ stretching). Moreover, CLAYFF can be extended by the use of an additional $\mathrm{M}-\mathrm{O}-\mathrm{H}$ harmonic bending potential, although this term is not generally used and not necessary to reproduce clay structures. We call the resulting force field "extended CLAYFF", and in this work we have used both CLAYFF and extended CLAYFF. We show later that the $\mathrm{M}-\mathrm{O}-\mathrm{H}$ bending potential is crucial for simulating imogolite nanotubes, especially for adsorption properties. 


\section{Results and discussion}

\section{Validation of the force field}

The CLAYFF force field has been used in the literature for classical molecular simulations of imogolite nanotubes, $\frac{12 \mid 1720}{20}$ owing to the similarities between clays and imogolite. Here, we set out to check its validity in the description of both neat imogolite nanotubes as well as water-filled tubes. As a reference, we compared it to trajectories obtained from first-principles molecular dynamics, where the evaluation of interatomic forces is done at the DFT level. We found that the structure of the nanotube itself is relatively rigid, and dictated by equilibrium $\mathrm{Si}-\mathrm{O}$ and $\mathrm{Al}-\mathrm{O}$ bond lengths, so that the skeleton (aluminum $\mathrm{Al}$, silicon $\mathrm{Si}$, and bridging oxygens $\mathrm{O}_{\mathrm{br}}$ ) is well reproduced with the CLAYFF potential (in both variants).
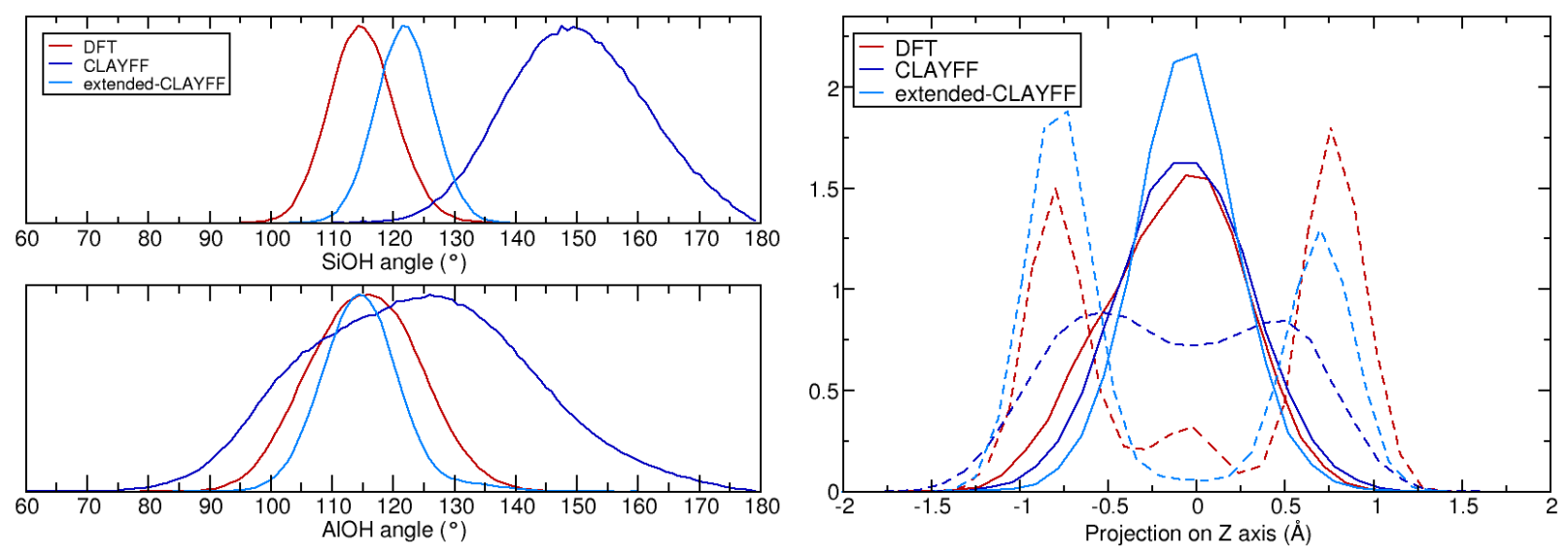

Figure 2: Left: angle distributions for $\mathrm{Si}-\mathrm{O}_{\text {int }}-\mathrm{H}_{\text {int }}$ angles (top) and $\mathrm{Al}-\mathrm{O}_{\text {ext }}-\mathrm{H}_{\text {ext }}$ angles (bottom) for DFT (red line), CLAYFF (dark blue line) and extended-CLAYFF (sky blue line) simulations. Right: density of the internal hydrogen atoms, $\mathrm{H}_{\mathrm{int}}$, along the nanotube axis $z$ for an empty nanotube (solid lines) and a fully hydrated nanotube (dashed lines). Data from DFT are shown in red, data from CLAYFF in dark blue, and from extended-CLAYFF in sky blue.

Secondly, we focus on the description of the inner and outer surface groups. We plot in Figure 2 the calculated distributions of $\mathrm{Si}-\mathrm{O}_{\text {int }}-\mathrm{H}_{\text {int }}$ angles for silanol groups inside the tube, and $\mathrm{Al}-\mathrm{O}_{\text {ext }}-\mathrm{H}_{\text {ext }}$ angles for $\mathrm{AlOH}$ groups on the outer surface. There are clear discrepancies between CLAYFF results and reference first principles data: average $\mathrm{M}-\mathrm{O}-\mathrm{H}$ 
angles are much larger, and their distribution broader. For CLAYFF, angles go all the way up to $180^{\circ}$ and, for $\mathrm{AlOH}$, down below $90^{\circ}$; this contrasts with the clearly Gaussian distributions obtained by DFT, and centered at $115^{\circ}$ and $117^{\circ}$, for $\mathrm{SiOH}$ and $\mathrm{AlOH}$ respectively.

In contrast, augmenting the CLAYFF force field with the additional $\mathrm{M}-\mathrm{O}-\mathrm{H}$ bending term (the "extended CLAYFF") leads to a clear improvement of the imogolite description. The distributions of both $\mathrm{SiOH}$ and $\mathrm{AlOH}$ angles are closer to those obtained from firstprinciples MD, although the match is not perfect - as could be expected for a generic force field without ad hoc reparameterization. The average value of the $\mathrm{SiOH}$ angle with extended CLAYFF is $122^{\circ}$, which is $7^{\circ}$ larger than the reference data. The same is true of the outer $\mathrm{AlOH}$ groups.

These discrepancies in imogolite structure strongly affect water-imogolite interactions, and from here water adsorption, structure and dynamics. To further assess the necessity of using the extended CLAYFF instead of CLAYFF, we performed simulations of fully hydrated nanotubes, and compared them against data from first-principles MD. On the right panel of Figure 2, we show the density profiles along the nanotube axis $z$ for the internal hydrogens. First, we observe that in the empty nanotube, the density distributions are all around $z=0$ (the plane in which are located the silicon atoms). This allows hydrogen-bonding with other silanol groups in the same $z=0$ plane. Secondly, upon hydration, there is a clear move of the $\mathrm{SiOH}$ hydrogen atoms toward symmetric positions at $\pm 0.75 \AA$, due to hydrogen bonding with the water molecules - a detailed analysis of this hydrated structure will be given below. This change in the $\mathrm{H}$ localization, which we observe in the first-principles $\mathrm{MD}$, is well reproduced by the extended CLAYFF force field. However, it is markedly different in regular CLAYFF, where we see a unique broad population with two bumps. Thus the distribution of internal hydrogen atoms, fundamental for adsorption studies and the description of hydrated imogolites, is best described by the extended CLAYFF model. This aspect has been recently studied by Pouvreau et al ${ }^{28}$ that similarly showed the necessity of a $\mathrm{M}-\mathrm{O}-\mathrm{H}$ bending term to properly describe basal and edge surfaces of gibbsite and brucite. From here on, we will 
use exclusively the extended CLAYFF force field.

\section{Water adsorption}

In order to characterize water adsorption in the gas phase and obtain physically meaningful water uptake values, we performed GCMC simulations for water pressure between 2 and $3600 \mathrm{~Pa}$. Full details of the simulations, done with two different water models (SPC and TIP4P05) are presented in Supporting Information, as well as isotherms. For computational reasons, rigid water models were preferred in the GCMC calculations. We observe (Figure S1) that the imogolite nanotube is hydrophilic, i.e. the filling occurs at a pressure below the bulk saturation pressure. This is in agreement with the affinity of water for silanol-rich surfaces, or

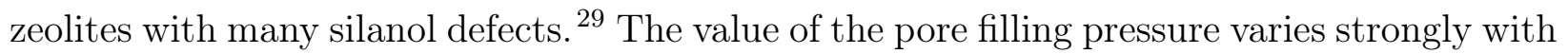
the nature of the model chosen for the description of the water, and the movement allowed for the silanol groups - consistent with the findings of Zang et al. 20 . We find transition pressures of $0.1 \mathrm{kPa}$ for TIP4P05, and $1 \mathrm{kPa}$ for the SPC water model. The order of magnitude of those values are within the range of experimental data, for example the gravimetric study of Konduri et al.17, which features a smooth isotherm with water uptake in the same range (0.1 to $1 \mathrm{kPa}$; see Figure S1).

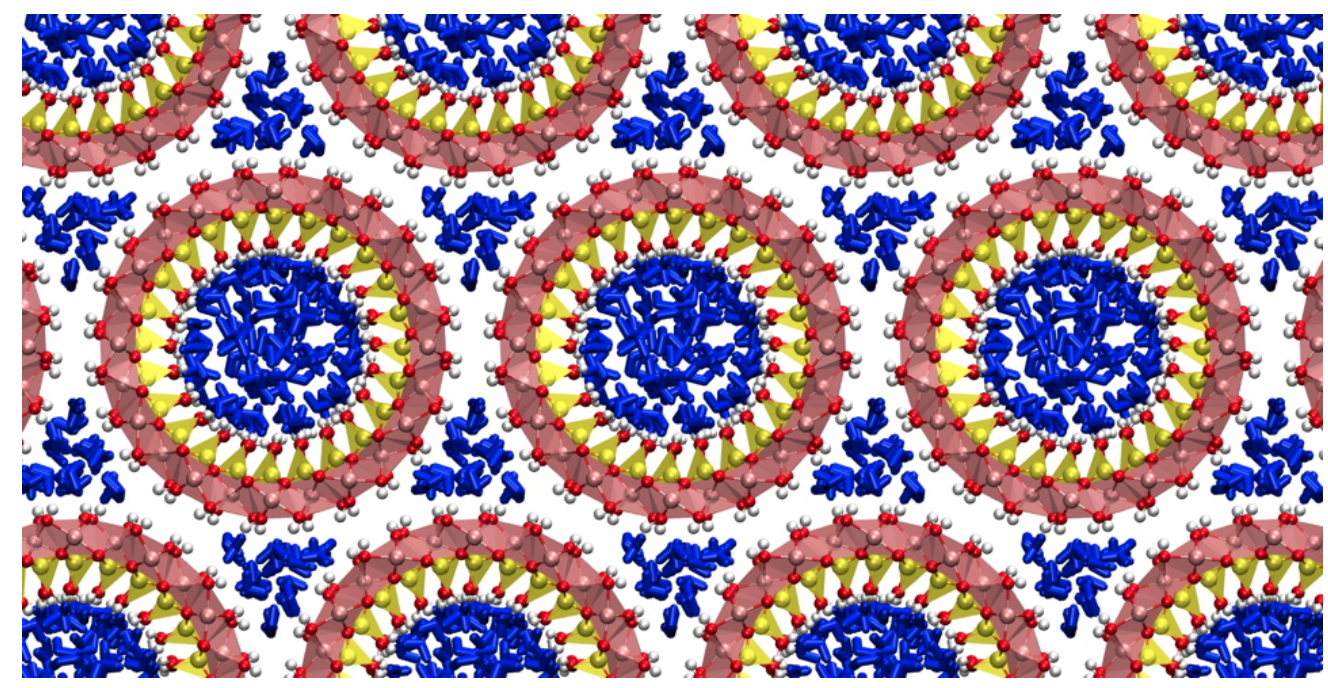

Figure 3: Fully hydrated imogolite nanotube $(n=12)$ with hexagonal packing. Water molecules are represented as blue sticks. 

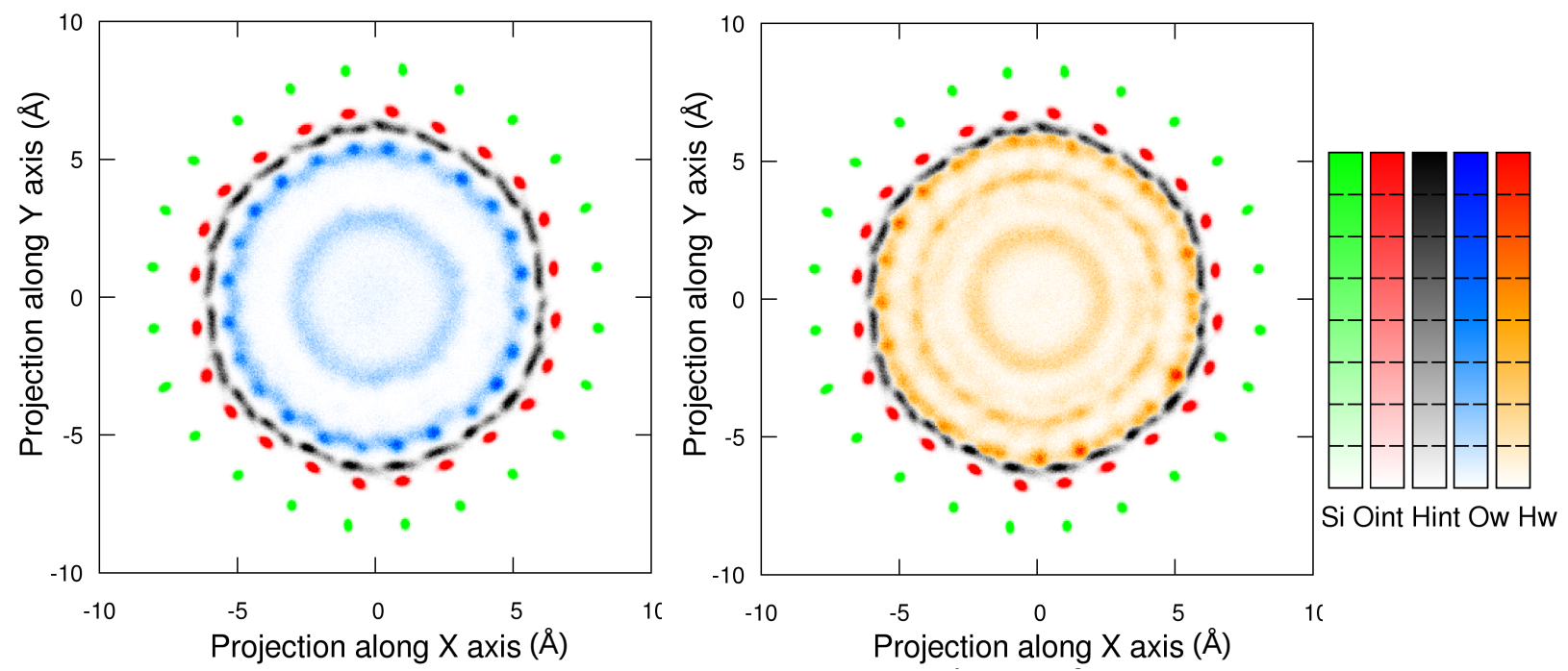

Figure 4: Two-dimensional density profiles in the $x y$ plane for atoms from the silanols groups $\left(\mathrm{Si}, \mathrm{O}_{\mathrm{int}}, \mathrm{H}_{\mathrm{int}}\right)$ and water molecules $\left(\mathrm{O}_{\mathrm{w}}\right.$ on the left pane, $\mathrm{H}_{\mathrm{w}}$ on the right pane).

In contrast to the adsorption pressure model dependence, there is a excellent agreement between the various models on the saturation uptake of water once the pore is filled, i.e. on the density of the water adsorbed inside the imogolite nanotube. Uptake is found to be $10 \%$ by weight after the transition, both for the SPC and TIP4P05 water models. We thus derived from the GCMC calculations an initial configuration for the simulation of the fully filled imogolite nanotube, from the plateau of the SPC adsorption isotherm. This initial configuration contains three nanotube $(n=12)$ unit cells along the $z$ axis, 98 water molecules inside the nanotubes and 18 water molecules outside. It is represented in Figure 3 . We used this fully hydrated tube as a starting configuration for classical molecular dynamics simulations, with the extended CLAYFF force field and ISPC water model.

\section{Structure of confined water}

From the analysis of the MD trajectories of the fully hydrated imogolite, we computed density profiles of all atom types (water $\mathrm{O}_{\mathrm{w}}$ and $\mathrm{H}_{\mathrm{w}}$; silanol groups $\mathrm{Si}, \mathrm{O}_{\text {int }}$, and $\mathrm{H}_{\text {int }}$ ). They are plotted in Figure 4 in the $x y$ plane, i.e. as if viewed "from the top" of the (infinite) nanotube. From the water oxygen distribution $\mathrm{O}_{\mathrm{w}}$, it is clear that there are two different 
populations of water molecules: strongly structured water adsorbed next to the inner surface (a first hydration layer, at distances between 4.5 and $5.8 \AA$ from the nanotube's center), and more disordered water filling up the center of the nanotube. This is also clearly visible in the cylindrical distribution functions (Figure S2), where we see that the two populations are not completely separate, i.e. the density does not fall to zero in-between. Furthermore, we see a slight deviation of the nanotube from a purely circular form: the position of the Si atoms show a slightly hexagonal deformation, due to the symmetry of the packing of nanotubes in bundles. $\frac{13}{13}$ This deformation is only very small, with Si displacements of 0.1 to $0.2 \AA$ at most, due to the rigid nature of the imogolite nanotube, especially with such a small diameter. This deformation is both linked to the hexagonal packing and the adsorption stress exerted by the water molecules - as shown previsouly for water/quartz interfaces, $\frac{30}{30}$ and more generally for adsorbates in "soft" porous materials. $\frac{31 \mid 32}{1 n}$ In the case of imogolite, the stress exerted is counterbalanced by the relative stiffness of the nanotube, although the extent and details of the deformation depend on the packing of the nanotubes. For example, Creton et al.14 used a larger distance between the nanotubes and observed a transition between an ellipsoid shape to a more cylindrical shape when increasing water densities.

To better understand the structuration of the first adsorbed layer, we plot in Figure 5 the same densities, but this time as a function of cylindrical coordinates $z$ and $\rho$, where $\rho$ is the distance to the central axis of the nanotube. There, the strongly preferential location for the confined water oxygen atoms becomes clear: the water molecules sit in the wider furrows, situated in-between two rings of silanol groups ( $\mathrm{SiOH}$ rings are situated every $4.25 \AA$ along the $z$ axis, and are depicted on Figure 5 by dotted lines). This preferential localization of the adsorbed water contrasts sharply with that of water inside carbon nanotubes, whose internal surface is smoother. It was, however, demonstrated in other nanopores of small dimensions with "dangling" hydroxyl groups accessible to the water for hydrogen-bonding. 33

These molecules are strongly hydrogen-bonded to the silanol groups, as indicated by the well-defined positions for $\mathrm{H}_{\mathrm{int}}$ atoms, which are rearranged compared to their relaxed 

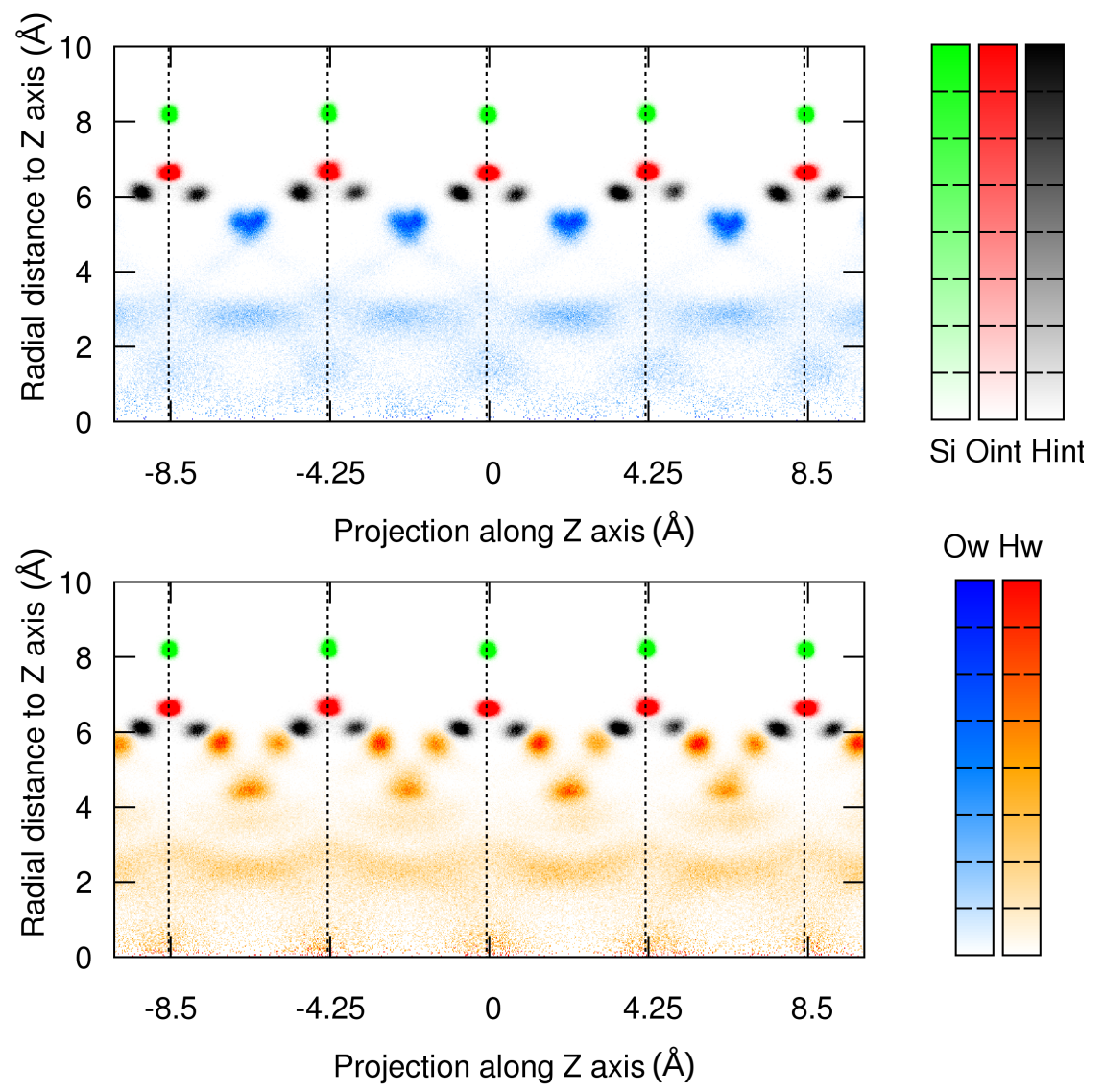

Figure 5: Two-dimensional density profiles (the radial dimension versus the projection along the $z$ axis) for surface atoms $\left(\mathrm{Si}, \mathrm{O}_{\text {int }}, \mathrm{H}_{\text {int }}\right)$ and water atoms $\left(\mathrm{O}_{\mathrm{w}}, \mathrm{H}_{\mathrm{w}}\right)$. Silicon rings are indicated by dashed lines. Density profiles are normalized, so that for each atom type the highest value is set to 1.0 (full color intensity).

position. Indeed, in the dry imogolite nanotube, the most stable position for the internal hydrogens is in the silanol ring plane $(z=0)$, where they are pointing toward a neighboring $\mathrm{O}_{\mathrm{int}}$ atom. This conformation allows the formation a relatively weak hydrogen bond, because the $\mathrm{O}_{\text {int }}-\mathrm{H}_{\mathrm{int}} \cdots \mathrm{O}_{\text {int }}$ distance is large. In the hydrated tube, the hydrogen atoms' most common position is shifted out of that silanol ring plane (see Figure 5). This is reflected by a change in the $\mathrm{O}_{\mathrm{br}}-\mathrm{Si}-\mathrm{O}_{\mathrm{int}}-\mathrm{H}_{\mathrm{int}}$ dihedral angle (see Figure S3), which goes from $0^{\circ}$ to $60^{\circ}$; where $\mathrm{O}_{\mathrm{br}}$ is the oxygen atom bridging the aluminum to the silicon.

We thus propose the following model to better visualize and understand the structure of the adsorbed water. We model the inner surface of the nanotube as a periodic sequence of triangles, where each silanol group $\mathrm{SiOH}$ is a vertex. The $\mathrm{Si}-\mathrm{Si}$ and $\mathrm{O}-\mathrm{O}$ radial distribution 

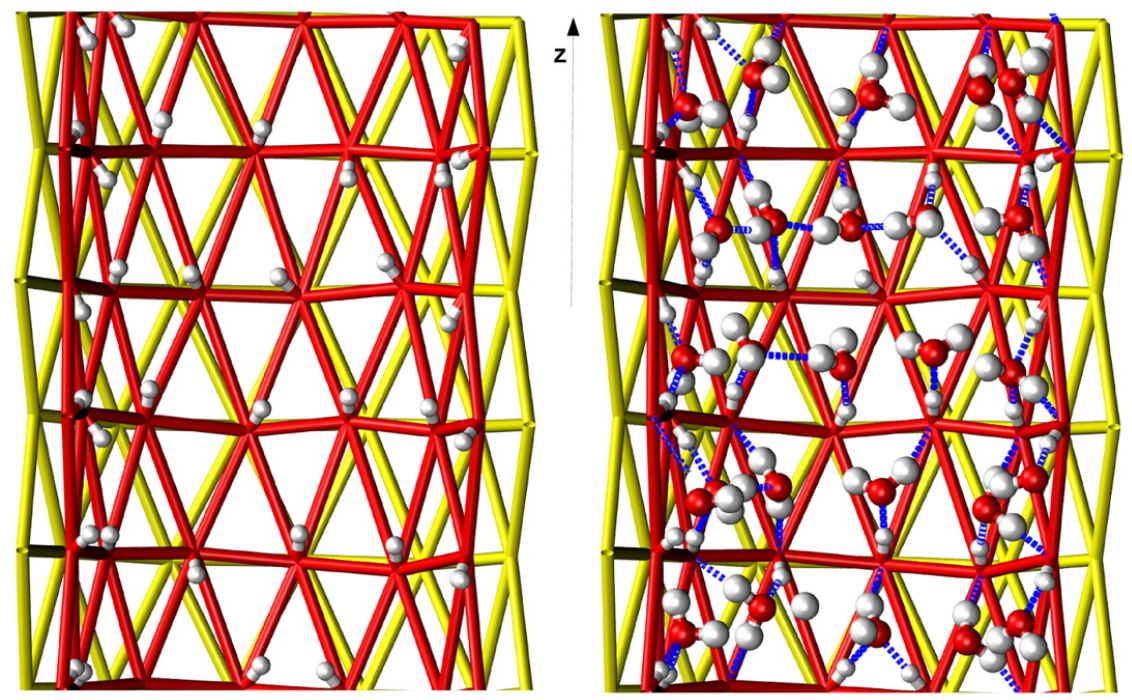

Figure 6: Illustration of the model on the $n=12$ nanotube (only half of the nanotube is shown). The triangular adsorption sites are highlighted by drawing yellow triangles between silicon atoms and red triangles between oxygen atoms. In the right panel, water molecules within the first adsorption layer are drawn and hydrogen bonds are depicted in dotted blue sticks.

functions show two first neighbor peaks at 4.2 and $4.7 \AA$ for silicon, and at 3.3 and $4.6 \AA$ for internal oxygens. This means that the triangles are isosceles with two angles of $66.5^{\circ}$ and one angle of $47^{\circ}$. This pattern is depicted on Figure 6. Above the center of each triangle is a potential water adsorption site. However, analysis of the sites show that no neighboring sites in the same $x y$ plane can be occupied at the same time, due to short-distance intermolecular repulsion of water molecules, so that at most half of the adsorption sites are occupied in the filled tube. Then, each of the hydrogen atoms of the $\mathrm{SiOH}$ groups that form the vertices of a triangle will point toward one of the three occupied neighboring adsorption sites.

A final visualization can be obtained by a density plot of $\mathrm{O}$ and $\mathrm{H}$ atoms, where the density is mapped against $z$ and a circular coordinate, as if a slice of the nanotube had been "cut and unrolled". These densities are presented in Figure 7. Red dotted lines show the $\mathrm{SiOH}$ rings, while orange dotted lines show the triangular mesh described above. The adsorption sites on top of each triangle are clearly visible. We further see that there is a strong anisotropy of the system, where there is possible circular movement of the water 
molecules in-between sites in the same $z$ plane, while there is no observed density crossing the silanol rings, as already observed by Creton et al.14. This shows that there is surface diffusion of water molecules, but only in the $x y$ plane. 


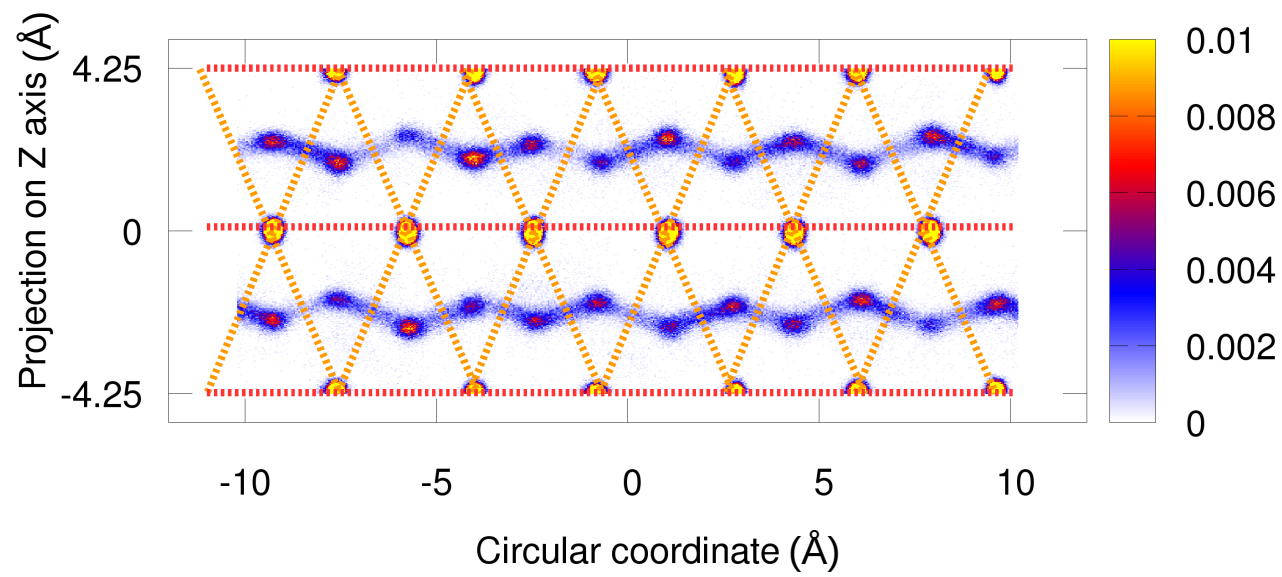

(a) Water oxygen

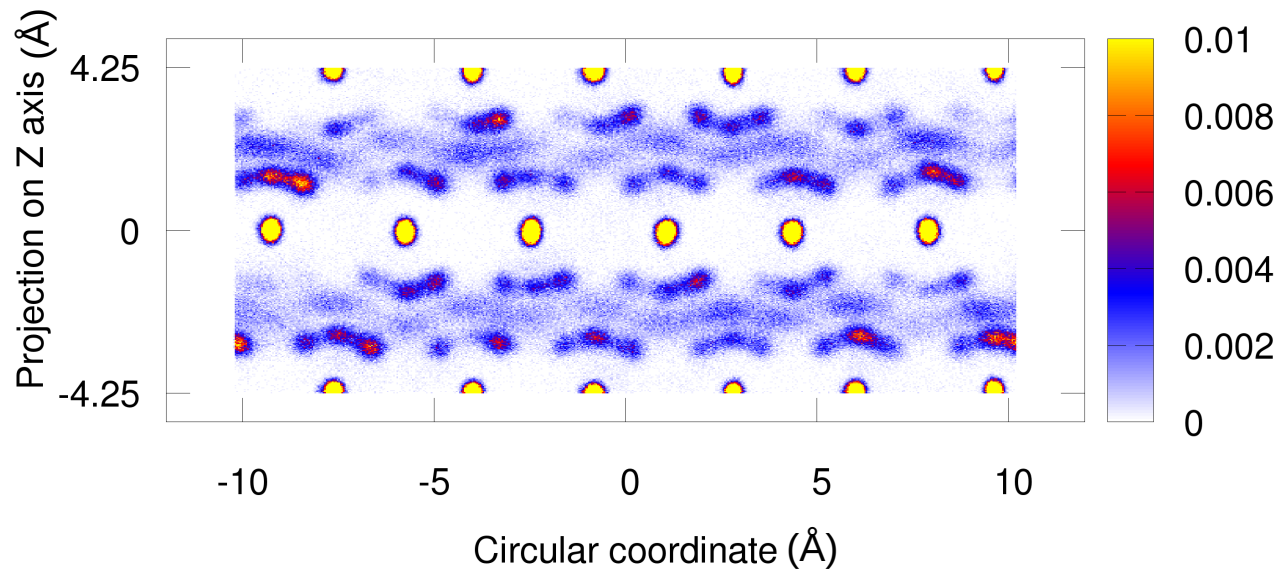

(b) Water hydrogen

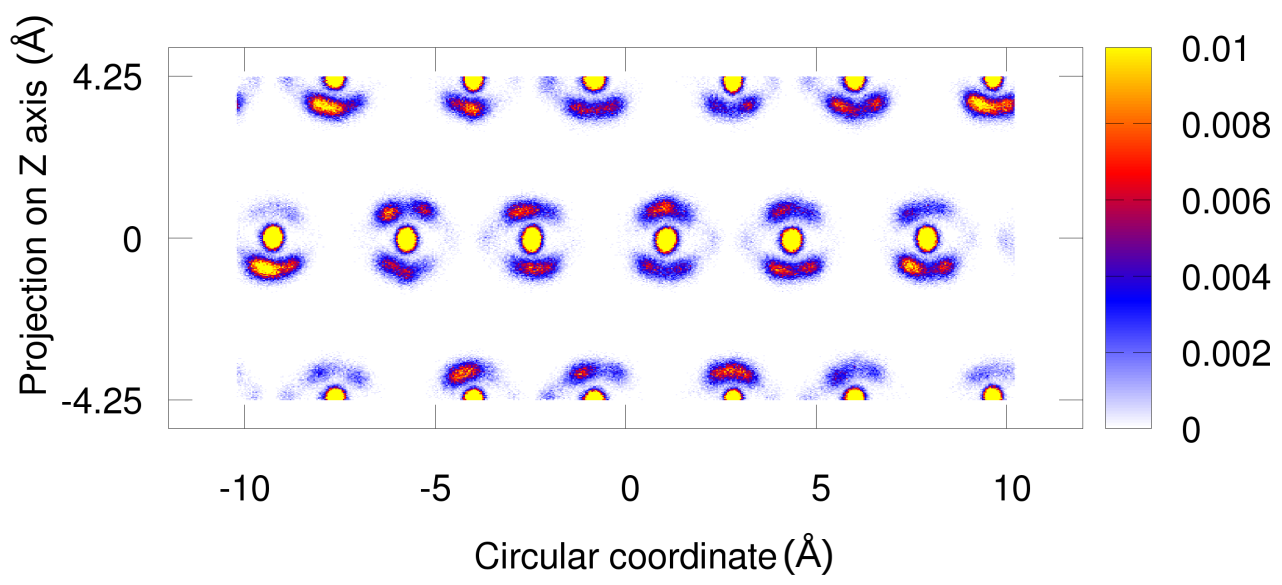

(c) Internal hydrogen

Figure 7: Density profiles on the flattened hydrated nanotube planes for water oxygen, water hydrogen and internal hydrogen. The circular coordinate corresponds to a curvilinear abscissa that draws a circle of radius $R=6.5 \AA$ centered on the axis $z$. On all the graphs, internal oxygens appear as yellow dots. 


\section{Hydrogen bond patterns}

The localization of the first layer of adsorbed water on the inner surface of the imogolite nanotube, and the strong hydrogen bonds that are created with the tube's silanol groups, make the first layer of water strongly ordered. We can see on Figure 5 (bottom panel) that this includes rotational ordering of the water molecules, with three marked preferential positions for their hydrogen atoms at room temperature. Two of those, equivalent by symmetry, correspond to the formation of a hydrogen bond, donated by the water molecule to the silanol group (acting as acceptor). The third position corresponds to a hydrogen atom "dangling" toward the inside of the nanotube. Because the water molecules have 2 hydrogen atoms that can occupy these positions, there are 3 possible geometries, summarized on Figure 8 , a water molecule can be donating two hydrogen bonds (case A); accepting one and donating one (case B); or accepting two hydrogen bonds from neighboring silanol groups (case C).

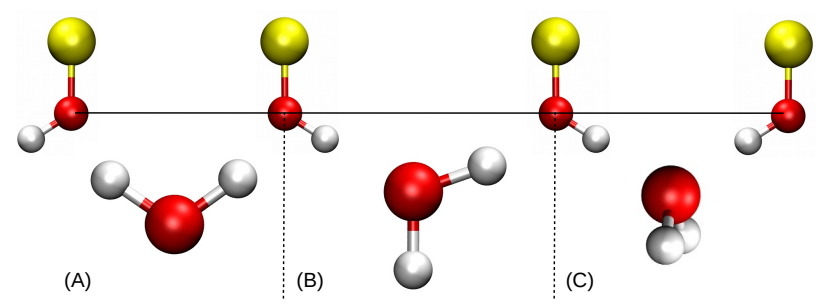

Figure 8: Three possible geometries of water adsorbed in the first layer of the imogolite inner surface.

In this section, we quantified the hydrogen-bond network and dynamics with a set of geometric criteria, that are commonly used in the literature for hydrogen bonds in water. We consider a hydrogen bond D- H - A to be present between donor atom D and acceptor atom $\mathrm{A}$ if, and only if, the $\mathrm{D} \cdots \mathrm{A}$ distance is less than $3.5 \AA$ and the $\widehat{\mathrm{HDA}}$ angle is less than $30^{\circ} . \underline{34}$ We performed hydrogen bond analysis on the hydrated and empty nanotubes, and differentiated the types of hydrogen bonds according to the donor and acceptor groups. Water hydroxyls and silanols can both be donor and acceptor.

The average number of hydrogen bonds formed during the trajectory is presented in 
Table 1: Average number of hydrogen bonds ( \pm the standard deviation) for given donoracceptor pairs along a $1 \mathrm{~ns}$ trajectory of empty and hydrated nanotubes. Total number of silanol groups: 72; total number of water molecules: 98.

\begin{tabular}{|c|c|c|c|}
\hline Donor & Acceptor & Empty Nanotube & Hydrated Nanotube \\
\hline Silanol & Silanol & $35.4 \pm 2.3$ & $2.0 \pm 1.3$ \\
\hline Water & Silanol & & $69.0 \pm 2.1$ \\
\hline Silanol & Water & & $68.7 \pm 1.7$ \\
\hline Water & Water & & $112.4 \pm 3.7$ \\
\hline
\end{tabular}

Table 2: Occurrence of the most recurrent patterns of hydrogen bonding characterized by the number of bonds given to silanol and water and received from silanol and water. Percentages are given with respect to the total number of water molecules.

\begin{tabular}{|c|c|c|c|c|c|}
\hline Pattern & Occurrence & $\begin{array}{c}\text { Donating } \\
\text { to silanol }\end{array}$ & $\begin{array}{c}\text { Accepting } \\
\text { from silanol }\end{array}$ & $\begin{array}{c}\text { Donating } \\
\text { to water }\end{array}$ & $\begin{array}{c}\text { Accepting } \\
\text { from water }\end{array}$ \\
\hline 1 & $22.4 \%$ & 0 & 0 & 2 & 2 \\
\hline 2 & $14.9 \%$ & 1 & 2 & 1 & 0 \\
\hline 3 & $9.3 \%$ & 2 & 1 & 0 & 1 \\
\hline 4 & $7.8 \%$ & 0 & 0 & 2 & 1 \\
\hline 5 & $7.3 \%$ & 1 & 1 & 1 & 1 \\
\hline 6 & $6.3 \%$ & 1 & 1 & 1 & 0 \\
\hline
\end{tabular}

Table 1. The change in silanol-silanol hydrogen bonding confirms the structural change upon adsorption: when the nanotube is empty, approximately half of the silanol groups are linked by a hydrogen bond within silicon rings (as detected per our rather strict criteria). When hydrated, only $2 \%$ form a hydrogen bond with another silanol group. Regarding the hydrogen bonds between a water molecule and the surface, $94 \%$ of the silanol groups donate a hydrogen bond to a water molecule and each silanol group receives on average 0.96 hydrogen bonds from water. Since a silanol group can donate only 1 hydrogen bond and can receive 1 or 2 hydrogen bonds, the bonding possibilities of the surface are extensively used. Within the nanotube, on average $57 \%$ of water molecules receive or donate at least one hydrogen bond from or to a silanol group, i.e. are in the first adsorbed layer.

To further characterize the local hydrogen bond network, we considered all 4 singular hydrogen bonding behaviors possible for a single water molecule: donating to a silanol or a water molecule, or accepting from either. Each of these singular behaviors can appear zero, 


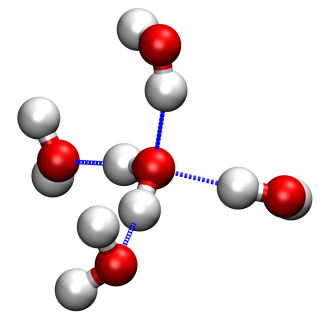

(a) Pattern 1

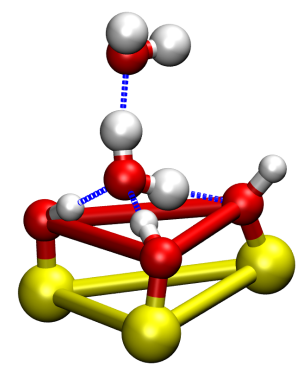

(b) Pattern 2

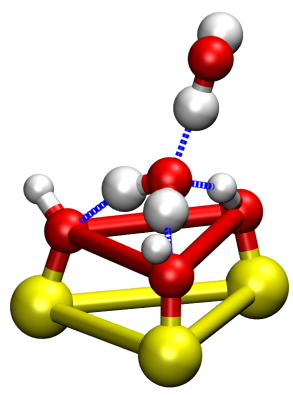

(c) Pattern 3

Figure 9: Illustration of the most common hydrogen bonding patterns for water in an imogolite nanotube. For the numbering of patterns, see Table 2.

once, or twice. The patterns that represent more than $5 \%$ of the occurences found over the whole trajectory are described in Table 2 .

The six patterns highlighted by this analysis can be divided in two groups: (i) water molecules that do not form any hydrogen bond with a silanol group (patterns 1 and 4), that can have either 4 hydrogen bonds (tetragonal arrangement) or $3 \mathrm{H}$ bonds, similarly to bulk water; and (ii) molecules whose adsorption on the inner surface of the nanotube involves at least one hydrogen bond (types 2, 3,5 and 6). It is worth noting that the mean number of hydrogen bonds for a water molecule not bonded to the surface is 3.65, slightly higher than the bulk value for fSPC water (3.60 hydroben bonds per water molecule). The most common patterns are represented in Figure 9. For adsorbed molecules, the most common pattern is an "upright" water molecule (pattern 2, Fig. 9b), in a plane bisecting the triangular adsorption site. This water molecule receives two $\mathrm{H}$ bonds from two silanol groups and donates one hydrogen bond to the third silanol. A water hydroxyl group is left pointing toward the center of the nanotube, free to donate a hydrogen bond to a water molecule of the second layer. This creates a structuration of the adsorbed water beyond the first layer, which is clearly visible in the density maps (Figures 4 and 5), with a favorable position for water oxygen atoms across that pending hydroxyl group. It also defines an equilibrium distance between the first and second layer of adsorption, which corresponds to a water-water hydrogen bond length. 
The second most common pattern for the first layer of water is a water molecule lying "flat" on the inner imogolite surface, donating two $\mathrm{H}$ bonds to neighboring silanol groups and receiving one from the third silanol neighbor. This allows the formation of a fourth hydrogen bond from a water molecule outside of the first layer. In this case the direction of the hydrogen bond is less constrained, explaining the "diffuse" part of the oxygen density in the second water layer, seen in Figure 5 .

The large possibilities of organization of the first layer of adsorbed water molecules, with orientational disorder, is reminiscent of the theory of Bernal and Fowler ${ }^{35}$ regarding ice rules. From the energetics of each individual configurations, as well as the frustration arising from constraints (no more than two $\mathrm{H}$ bonds can be donated or received, and no two neighboring adsorption sites can be populated at the same time), we believe that a model of the orientational disorder in that strongly bound layer of adsorbed water could be constructed, possibly explaining why the adsorption sites are only occupied at nearly $38 \%$ at saturation uptake.

\section{Water dynamics}

From the structural analysis of the water density and the hydrogen bonds in the adsorbed water, there are clear hints at the dynamic nature of the system and the lability of the water

molecules. We have seen that hydrogen bond patterns are statistically distributed among several configurations, and that there is anisotropic surface diffusion in the first layer of adsorbed water (see Figure 7 and accompanying text). Analysis of trajectories shows that this surface diffusion occurs without breaking all the hydrogen bonds involved. By breaking a single hydrogen bond, an adsorbed water molecule can flip around the axis formed by the remaining silanol groups, and thereby diffuses to the adjacent site, then reforms a hydrogen bond with another $\mathrm{SiOH}$ group. Since the triangular sites are isosceles and the surface is curved, the flip is easier and requires less configurational change within the furrows, than crossing the silicon rings. This explains the preferential circular diffusion as opposed to 


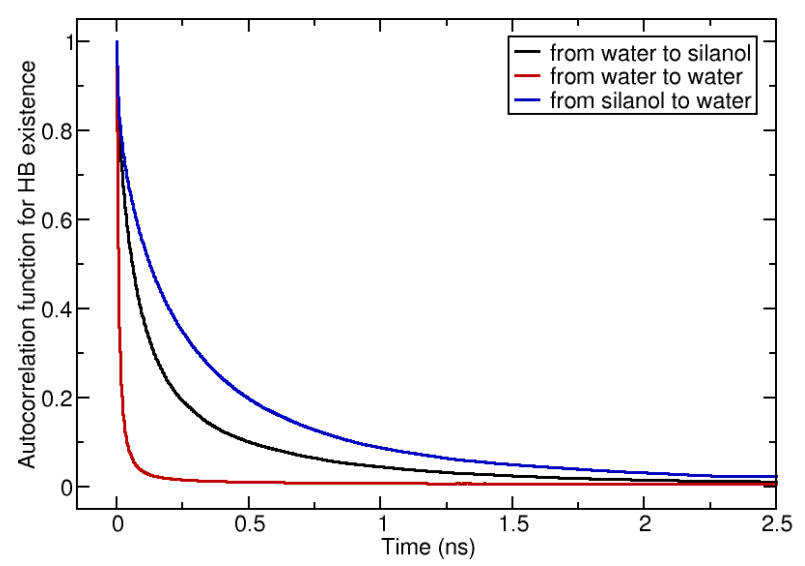

(a)

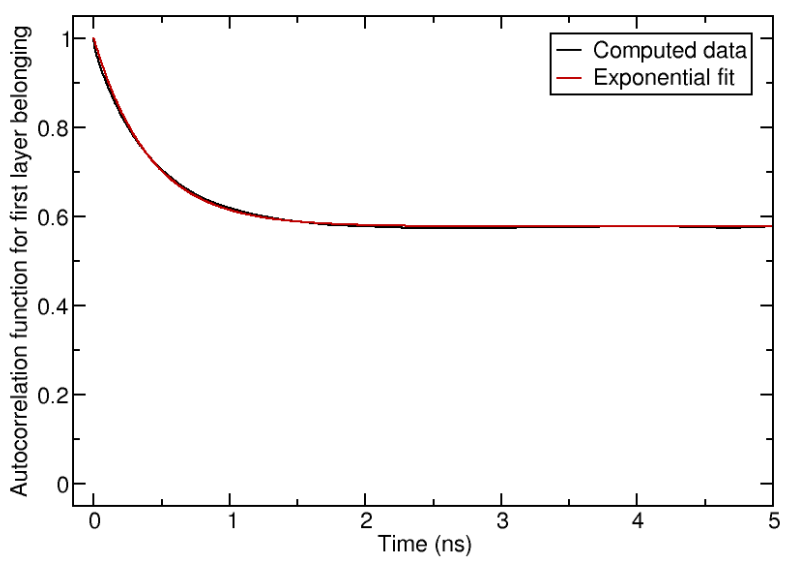

(b)

Figure 10: (a) Autocorrelation of the hydrogen bond existence for three types of donoracceptor couples: water-silanol (black line), silanol-water (blue line) and water-water (red line).

(b) Autocorrelation of presence in the first adsorbed layer. The computed data (black line) was fitted by an exponential function (red line), $y=1+0.42\left(\exp \left(-\frac{x}{0.41}\right)-1\right)$.

Table 3: Characteristic lifetime for hydrogen bonds calculated from the time length for the autocorrelation function to decay to $50 \%$.

\begin{tabular}{|c|c|c|}
\hline Donor & Acceptor & Characteristic time $\tau$ \\
\hline Water & Water & $4.43 \mathrm{ps}$ \\
\hline Water & Silanol & $57.43 \mathrm{ps}$ \\
\hline Silanol & Water & $123.5 \mathrm{ps}$ \\
\hline
\end{tabular}

the axial diffusion in fully loaded nanotube. In this section, we go further to quantify the dynamics of the water inside the imogolite nanotube.

To do so, we calculated autocorrelation functions of the presence of water molecules, both within the first adsorption layer and in the less-ordered "core" of the tube. Due to the relatively slow dynamics of the strongly-confined water, these quantities were calculated from 50 ns classical trajectories. For all three possible donor-acceptor hydrogen bond types, we computed autocorrelation functions which are plotted in Figure 10a. From these autocorrelation functions, the lifetime of each $\mathrm{H}$ bond type was extracted, and are presented in Table 3. The autocorrelation decay is not stricly exponential, because the hydrogen bonds form multiple populations (first and second layer, etc.) with different decays. 
First, looking at the water-water hydrogen bonds, we see that their lifetime is roughly 2 times higher in the imogolite nanotube than in bulk water (calculated at 2.67 ps from a simulation of pure fSPC water). This slow down of the water dynamics under confinement has been well studied and explained in previous work, and is due in part to the stronger organization of the water, and in part to excluded volume effects (a water molecule finding fewer partners to "switch" a hydrogen bond to). 36137 Secondly, we see that hydrogen bonds between water and the silanol-rich surface have a lifetime more than an order of magnitude greater than water-water $\mathrm{H}$ bonds. A study on hydrogen bonding of water on the $\alpha$-quartz interface - whose (001) surface is chemically similar to imogolite, in that it presents geminal silanol groups — calculated persistence times of $\mathrm{SiOH}$-water hydrogen bonds between 160 and 170 fs. $\frac{38}{38}$ The extremely large difference, and the very strong bonding of water on the imogolite inner surface, can be explained by the cooperative effect of the formation of three hydrogen bonds, on top of which is present the generic confinement slow-down.

We also investigated the residence time of water molecules in the first adsorbed layer, inside the imogolite nanotube. There are two ways to define the "first layer", by using geometrical radius, or by considering molecules that form at least one hydrogen bond with the surface. We chose the latter option, which is more chemically robust. The time autocorrelation function deriving from it is plotted in Figure 10b. It shows an exponential decay, and reaches a plateau at $57 \%$, i.e. the average percentage of water molecules that belong to that first layer. The decay time for the autocorrelation function is found to be $410 \mathrm{ps}$. This is two or four times larger than the indicative lifetimes of hydrogen bonds with the surface (donated or received by the silanol group, respectively). This confirms the existence of an "inner surface diffusion" mechanism that allows diffusion between adsorption sites without exiting the layer itself. We can also compare this lifetime to residence times in protein adsorption sites. For example, for myoglobin $\frac{39}{}$, residence times span from 10 to 450 ps where the unusually high residence times ( $>80 \mathrm{ps}$ ) correspond to water trapped either in the cavities inside the protein or in the grooves and concave regions. 
To complete this study, we extracted diffusion coefficients from mean square displacement (Figure S4) of water molecules in the nanotube. We find a diffusion coefficient in the $z$ axis of

$3.510^{-6} \mathrm{~cm}^{2} / \mathrm{s}$, which is three times smaller than the coefficient calculated by Zang et al. .00 for a similar but lower water density. Moreover, we do not see a long-time diffusive behavior in the $x y$ plane because of the confinement.

\section{Conclusions and perspectives}

This study of the properties of water adsorbed inside hydrophilic imogolite nanotubes was motivated by the understanding of the specific behavior of water due to its tight confinement, with numerous silanol groups on the inner surface of the nanotubes. Because the strong interactions between water and imogolite, and the slow dynamics of the confined water, we relied on a classical force field in order to perform molecular dynamics studies. We validated the CLAYFF force field, and found that it had to be employed in its extended version with a $\mathrm{Si}-\mathrm{O}-\mathrm{H}$ bending term - in order to correctly reproduce the reference data we had produced from first-principles molecular dynamics. This is in contrast with conventional clay materials, where this term is not as important, and is ascribed to the strong curvature of the imogolite surface.

We then developed a model for the structure of adsorbed water, based on the calculated atomic densities and statistical analysis of the hydrogen bonding patterns observed between water molecules and silanol groups. We show that adsorption in the first layer vicinal to the imogolite tube can be described by an anisotropic triangular lattice of adsorption sites, which are not fully populated. We showed that interactions between the water molecules adsorbed at neighboring sites are complex, based on (i) exclusion of some nearest neighbor pairs (where the sites are too close to be occupied at the same time), and (ii) the number of hydrogen bonds donated (and accepted) by the water molecules to (and from) neighboring silanol groups. Maximizing the number of hydrogen bonds created, while adhering to these 
rules, creates frustration in the system and leads to the emergence of a heavily disordered state. This situation is very similar to the Bernal-Fowler rules describing the orientation of water molecules in ice. $\frac{35}{35}$ Finally, we also characterized the dynamics of the confined water molecules, as well as the hydrogen bonds. We find that in addition to the generic effect of slow-down of confined water, the strong interactions of water molecules with the silanol groups giving rise to lifetimes that compare to typical residence times of water in protein adsorption sites.

In the future, it would be interesting to extend this study of the structure of adsorbed water at varying temperature, or with changes in the imogolite nanotube size (from the value of $n=12$ repeating units used in this study). Another noteworthy perspective would be to consider the possibility of partial or total functionalization of the silanol groups replacing for example some of the hydrophilic $-\mathrm{SiOH}$ groups with hydrophobic $-\mathrm{SiOCH}_{3}$. This would affect the overall affinity of the internal surface of the imogolite nanotubes for water, tuning them from very hydrophilic to potentially hydrophobic, $\frac{41}{1}$ and changing the thermodynamics of adsorption. It would also introduce more frustration into the adsorbed water and change the "ice rules", affecting the structure of the confined phase. This could be studied by atomistic simulations, as was done here, or at a more fundamental scale by an Ising-type model of the adsorbed water molecules, dictated by the energies of the various possible configurations of neighbording water molecules and silanol groups.

\section{Supporting Information}

Description of the Grand Canonical Monte Carlo adsorption models, adsorption isotherms, additional structural information, and mean-square displacement of adsorbed water. 


\section{Acknowledgements}

We thank Antoine Thill, Sophie Le Caer, and Yuanyuan Liao for fruitful discussions. We acknowledge access to the CINES High Performance Computing platforms provided by a GENCI grant (A0030807069). 


\section{References}

(1) Yoshinaga, N.; Aomine, S. Imogolite in some ando soils. Soil Sci. Plant Nutr. 1962, 8, 22-29.

(2) Amara, M.-S.; Paineau, E.; Bacia-Verloop, M.; Krapf, M.-E. M.; Davidson, P.; Belloni, L.; Levard, C.; Rose, J.; Launois, P.; Thill, A. Single-step formation of micron long $(\mathrm{OH}) 3 \mathrm{Al} 2 \mathrm{O} 3 \mathrm{Ge}(\mathrm{OH})$ imogolite-like nanotubes. Chem. Commun. 2013, 49, 11284.

(3) Gustafsson, J. P. The Surface Chemistry of Imogolite. Clays Clay Miner. 2001, 49, $73-80$.

(4) Guimarães, L.; Enyashin, A. N.; Frenzel, J.; Heine, T.; Duarte, H. A.; Seifert, G. Imogolite Nanotubes: Stability, Electronic, and Mechanical Properties. ACS Nano 2007, 1, $362-368$.

(5) Tamura, K.; Kawamura, K. Molecular Dynamics Modeling of Tubular Aluminum Silicate: Imogolite. J. Phys. Chem. B 2002, 106, 271-278.

(6) Zhao, M.; Xia, Y.; Mei, L. Energetic Minimum Structures of Imogolite Nanotubes: A First-Principles Prediction. J. Phys. Chem. C 2009, 113, 14834-14837.

(7) Demichelis, R.; Noël, Y.; D’Arco, P.; Maschio, L.; Orlando, R.; Dovesi, R. Structure and energetics of imogolite: a quantum mechanical ab initio study with B3LYP hybrid functional. J. Mater. Chem. 2010, 20, 10417.

(8) Alvarez-Ramírez, F. Ab initio simulation of the structural and electronic properties of aluminosilicate and aluminogermanate nanotubes with imogolite-like structure. Phys. Rev. B 2007, 76, 125421.

(9) Konduri, S.; Mukherjee, S.; Nair, S. Controlling Nanotube Dimensions: Correlation between Composition, Diameter, and Internal Energy of Single-Walled Mixed Oxide Nanotubes. ACS Nano 2007, 1, 393-402. 
(10) Lee, S. U.; Choi, Y. C.; Youm, S. G.; Sohn, D. Origin of the Strain Energy Minimum in Imogolite Nanotubes. J. Phys. Chem. C 2011, 115, 5226-5231.

(11) González, R. I.; Ramírez, R.; Rogan, J.; Valdivia, J. A.; Munoz, F.; Valencia, F.; Ramírez, M.; Kiwi, M. Model for Self-Rolling of an Aluminosilicate Sheet into a SingleWalled Imogolite Nanotube. J. Phys. Chem. C 2014, 118, 28227-28233.

(12) González, R. I.; Rogan, J.; Bringa, E. M.; Valdivia, J. A. Mechanical Response of Aluminosilicate Nanotubes under Compression. J. Phys. Chem. C 2016, 120, 1442814434.

(13) Amara, M. S.; Rouzière, S.; Paineau, E.; Bacia-Verloop, M.; Thill, A.; Launois, P. Hexagonalization of Aluminogermanate Imogolite Nanotubes Organized into ClosedPacked Bundles. J. Phys. Chem. C 2014, 118, 9299-9306.

(14) Creton, B.; Bougeard, D.; Smirnov, K. S.; Guilment, J.; Poncelet, O. Molecular dynamics study of hydrated imogolite : 2. Structure and dynamics of confined water. Phys. Chem. Chem. Phys. 2008, 10, 4879.

(15) Cradwick, P. D. G.; Farmer, V. C.; Russell, J. D.; Masson, C. R.; Wada, K.; Yoshinaga, N. Imogolite, a Hydrated Aluminium Silicate of Tubular Structure. Nature Phys. Sci. 1972, 240, 187-189.

(16) Aroyo, M. I.; Perez-Mato, J. M.; Capillas, C.; Kroumova, E.; Ivantchev, S.; Madariaga, G.; Kirov, A.; Wondratschek, H. Bilbao Crystallographic Server: I. Databases and crystallographic computing programs. Z. Kristallogr. Cryst. Mater. 2006, 221, 15-27.

(17) Konduri, S.; Tong, H. M.; Chempath, S.; Nair, S. Water in Single-Walled Aluminosilicate Nanotubes: Diffusion and Adsorption Properties. J. Phys. Chem. C 2008, 112, $15367-15374$. 
(18) Ackerman, W. C.; Smith, D. M.; Huling, J. C.; Kim, Y. W.; Bailey, J. K.; Brinker, C. J. Gas/vapor adsorption in imogolite: a microporous tubular aluminosilicate. Langmuir 1993, 9, 1051-1057.

(19) Mukherjee, S.; Bartlow, V. M.; Nair, S. Phenomenology of the Growth of SingleWalled Aluminosilicate and Aluminogermanate Nanotubes of Precise Dimensions. Chem. Mater. 2005, 17, 4900-4909.

(20) Zang, J.; Chempath, S.; Konduri, S.; Nair, S.; Sholl, D. S. Flexibility of Ordered Surface Hydroxyls Influences the Adsorption of Molecules in Single-Walled Aluminosilicate Nanotubes. J. Phys. Chem. Lett. 2010, 1, 1235-1240.

(21) Dovesi, R.; Orlando, R.; Erba, A.; Zicovich-Wilson, C. M.; Civalleri, B.; Casassa, S.; Maschio, L.; Ferrabone, M.; De La Pierre, M.; D’Arco, P.; Noël, Y.; Causà, M.; Rérat, M.; Kirtman, B. CRYSTAL14: A program for the ab initio investigation of crystalline solids. Int. J. Quantum Chem. 2014, 114, 1287-1317.

(22) Hutter, J.; Iannuzzi, M.; Schiffmann, F.; VandeVondele, J. CP2K: atomistic simulations of condensed matter systems. WIREs Comput. Mol. Sci. 2014, 4, 15-25.

(23) Bussi, G.; Donadio, D.; Parrinello, M. Canonical sampling through velocity rescaling. J. Chem. Phys. 2007, 126, 014101.

(24) Plimpton, S. Fast Parallel Algorithms for Short-Range Molecular Dynamics. J. Comput. Phys. 1995, 117, 1-19.

(25) Desbiens, N.; Boutin, A.; Demachy, I. Water Condensation in Hydrophobic Silicalite-1 Zeolite: A Molecular Simulation Study. J. Phys. Chem. B 2005, 109, 24071-24076.

(26) Cygan, R. T.; Liang, J.-J.; Kalinichev, A. G. Molecular Models of Hydroxide, Oxyhydroxide, and Clay Phases and the Development of a General Force Field. J. Phys. Chem. B 2004, 108, 1255-1266. 
(27) Teleman, O.; Jönsson, B.; Engström, S. A molecular dynamics simulation of a water model with intramolecular degrees of freedom. Mol. Phys. 1987, 60, 193-203.

(28) Pouvreau, M.; Greathouse, J. A.; Cygan, R. T.; Kalinichev, A. G. Structure of Hydrated Gibbsite and Brucite Edge Surfaces: DFT Results and Further Development of the ClayFF Classical Force Field with Metal-O-H Angle Bending Terms. The Journal of Physical Chemistry C 2017, 121, 14757-14771.

(29) Coudert, F.-X.; Cailliez, F.; Vuilleumier, R.; Fuchs, A. H.; Boutin, A. Water nanodroplets confined in zeolite pores. Faraday Discuss. 2009, 141, 377-398.

(30) Gor, G. Y.; Bernstein, N. Adsorption-Induced Surface Stresses of the Water/Quartz Interface: Ab Initio Molecular Dynamics Study. Langmuir 2016, 32, 5259-5266.

(31) Neimark, A. V.; Coudert, F.-X.; Boutin, A.; Fuchs, A. H. Stress-Based Model for the Breathing of Metal-Organic Frameworks. J. Phys. Chem. Lett. 2009, 1, 445-449.

(32) Mouhat, F.; Bousquet, D.; Boutin, A.; Bouëssel du Bourg, L.; Coudert, F.-X.; Fuchs, A. H. Softening upon Adsorption in Microporous Materials: A Counterintuitive Mechanical Response. J. Phys. Chem. Lett. 2015, 6, 4265-4269.

(33) Haigis, V.; Coudert, F.-X.; Vuilleumier, R.; Boutin, A. Investigation of structure and dynamics of the hydrated metal-organic framework MIL-53(Cr) using first-principles molecular dynamics. Phys. Chem. Chem. Phys. 2013, 15, 19049.

(34) Luzar, A.; Chandler, D. Hydrogen-bond kinetics in liquid water. Nature 1996, 379, $55-57$.

(35) Bernal, J. D.; Fowler, R. H. A Theory of Water and Ionic Solution, with Particular Reference to Hydrogen and Hydroxyl Ions. J. Chem. Phys. 1933, 1, 515-548.

(36) Fogarty, A. C.; Coudert, F.-X.; Boutin, A.; Laage, D. Reorientational Dynamics of Water Confined in Zeolites. ChemPhysChem 2014, 15, 521-529. 
(37) Fogarty, A. C.; Duboué-Dijon, E.; Laage, D.; Thompson, W. H. Origins of the nonexponential reorientation dynamics of nanoconfined water. J. Chem. Phys. 2014, 141, $18 \mathrm{C} 523$.

(38) Ozkanlar, A.; Kelley, M.; Clark, A. Water Organization and Dynamics on Mineral Surfaces Interrogated by Graph Theoretical Analyses of Intermolecular Chemical Networks. Minerals 2014, 4, 118-129.

(39) Makarov, V. A.; Andrews, B. K.; Smith, P. E.; Pettitt, B. M. Residence Times of Water Molecules in the Hydration Sites of Myoglobin. Biophys. J. 2000, 79, 2966-2974.

(40) Zang, J.; Konduri, S.; Nair, S.; Sholl, D. S. Self-Diffusion of Water and Simple Alcohols in Single-Walled Aluminosilicate Nanotubes. ACS Nano 2009, 3, 1548-1556.

(41) Bonelli, B. Developments in Clay Science; Elsevier, 2016; Vol. 7; pp 279-307. 


\section{Graphical TOC Entry}

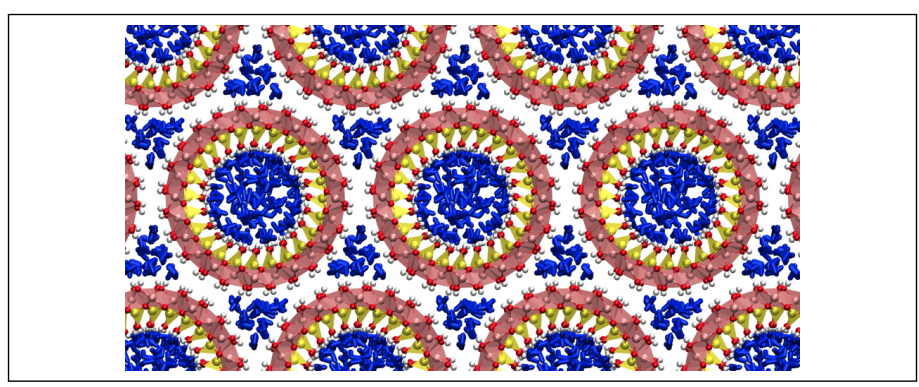

